\title{
Interactive comment on "Quantifying the effect of forests on occurrence frequency and intensity of rockfalls" by Christine Moos et al.
}

\section{Anonymous Referee \#1}

Received and published: 17 August 2016

Title

As the paper essentially deals with the impact frequency of blocks and not the occurrence frequency of rockfalls, it is suggested to replace "occurrence frequency" by "impact frequency". Moreover, forest can't influence rockfall occurrence because rockfalls initiate usually in the upper part of slopes, before the falling blocks can be influenced by forest.

\section{General comment}

The paper deals with the influence of forest on the impact (or potential impact) frequency and intensity of rock blocks. It is well written and understandable. The influence of forest is clearly demonstrated for a virtual slope, despite a confusion between the rockfall volume distribution and the block volume distribution. Correction of this

Printer-friendly version

Discussion paper 
confusion needs a revision of the paper. Moreover, the terminology used in the paper is not sufficiently accurate and needs to be modified.

Specific comments

1. The input data which are used for the simulation of blocks propagation are derived from Carrea et al. (2015). But Carrea et al. (2005) give the distribution of the volumes of rockfall events and not of the individual blocks. Similarly, the cited references (Dussauge-Peisser et al., 2002; Malamud et al., 2004) don't deal with the distribution of block volumes. Studies on the distribution of block volumes can be found in the following references: Ruiz-Carulla, R., Corominas, J. \& Mavrouli, O. 2015. A methodology to obtain the block size distribution of fragmental rockfall deposits. Landslides, 12: 815825. Hantz D., Ventroux Q., Rossetti J-P., Berger F. 2016. A new approach of diffuse rockfall hazard. In: Landslides and Engineered Slopes - Aversa et al. (Eds). Associazione Geotecnica Italiana, Rome, Italy, ISBN 978-1-138-02988-0, 1063-1067. This confusion doesn't call into question the results obtained because (a) the simulation has been made on a virtual slope which is not the La Cornalle slope, (b) the values used for the power-law parameters are plausible also for the distribution of block volumes. But the section 2.2 should be rewritten without mentioning the unsuitable references (Dussauge-Peisser et al., 2002; Malamud et al., 2004; Carrea et al., 2005).

2. In the widely used terminology of landslides (Varnes, 1978; Cruden \& Varnes, 1996), the word "rock" refers to the material which is implied in the movement and not to the fragments which propagate down ther slope. The fragments implied in a rockfall can be called fragments, particles, projectiles (Bourrier, Dorren, Hungr, 2013), but the word "block" is more commonly used (for example, Ruiz-Carulla, Corominas, Mavrouli, 2016, Comparison of block size distribution in rockfalls). Then I suggest to replace "rock" by "block" in some places. Moreover, a rockfall event consists in two phases: The detachment of a volume of rock from a steep slope and its propagation down the slope (for example, Bourrier, Dorren, Hungr, 2013). When mentioning a frequency, it is important to precise if it is a detachment (or release) frequency or an impact frequency

Printer-friendly version Discussion paper 
on an element at risk. The expression "occurrence frequency" used in the manuscript is not explicit, so I suggest to replace it by "release frequency" or "impact frequency".

Page 3, line 6-9 I don't understand what are "reference situations". Could you explain?

Page 4, line 7 Could you please explain why it is necessary to randomly vary the slope angle of each cell?

Interactive

comment

Page 4, line 9 It should be explained why a vertical fall height of $10 \mathrm{~m}$ has been chosen (it is not realistic).

Page 4, line 10 The distances are different from the distances in the Figure 1. For example, the last line must be at a distance of $574-100=474 \mathrm{~m}$ from the release area (and not $530 \mathrm{~m}$ ). This point must be clarified.

Page 5, line 31 The 49 scenarios should be explained: 4 forest types and 4 forest structures give 16 scenarios, but how can one obtain 49 scenarios? The number of slope scenarios doesn't appear clearly in Table 1 (2 soil types and 2 roughness scenarios give 4 slope scenarios!)

Page 7, line 2 Power-laws were fitted for the volume-frequency relation, but the powerlaw parameters (alpha and beta) are not given in the paper. It would be interesting to compare the beta-values obtained with the beta-value adopted for the initial distribution of block volume. Concerning the intensity-frequency relation, could you please indicate if the E95 values have been averaged over the 100 simulations to obtain the distribution shown in Figure 9? In other words, is the distribution obtained from 239 E95 values $(478 \mathrm{~m} / 2 \mathrm{~m}$ ) or from 23,900 values (dividing the number of each energy class by 100,000 years)? In my opinion, the most significant distribution in terms of hazard assessment would have been obtained by considering all the energies calculated in all cells rather than only the 95th percentiles (which doesn't contain all the information about the extreme values).

Page 7, line 15-20 The definitions of $b A$ and cbA should be clarified. From the definition

Printer-friendly version

Discussion paper 
given in the line $17, \mathrm{bA}$ is not an area, but a relative area which reflect the proportion of area which is occupied by trees. It should be called "relative basal area". As bA is dimensionless (m2/ha), it should be multiplied by an area to obtain a total tree area, which influences the impact frequency. I suggest to present the definition as follows: "The latter is defined as the product of the basal area (bA; m2/ha) by the area of the forested slope from the top of the release area to the respective EL, for a width of 100 m." And to define fsL after Equation (7) as the forested slope length. As cbA is an area, it must be expressed in $\mathrm{m} 2$, and not in m2ha-1 as written in Equation (7), page 11, line 6-7 and in Table 5. Moreover, in the third member of Equation (7) bA represents the basal area of individual trees and not the (relative) basal area as defined previously. I suggest to remove this third member which is incorrect and unnecessary.

Minor corrections are suggested in the pdf.

Please also note the supplement to this comment:

http://www.nat-hazards-earth-syst-sci-discuss.net/nhess-2016-230/nhess-2016-230RC1-supplement.pdf

Interactive comment on Nat. Hazards Earth Syst. Sci. Discuss., doi:10.5194/nhess-2016-230, 2016. 